\title{
An emerging multidrug-resistant bacteria
}

\author{
Jennie Johnstone MD PhD, Samir N. Patel PhD, on behalf of the Provincial Infectious Diseases Advisory \\ Committee - Infection Prevention and Control (PIDAC-IPC)*
}

Cite as: CMAJ 2017 September 5;189:E1115. doi: 10.1503/cmaj.170110

CMAJ Podcasts: author interview at https://soundcloud.com/cmajpodcasts/170110-five

\section{Carbapenemase-producing Enterobacteriaceae (CPE) are emerging 1 multidrug-resistant bacteria}

Carbapenemase-producing Enterobacteriaceae (CPE) are gram-negative bacteria (e.g., Escherichia coli, Klebsiella sp.) that are resistant to most antibiotics, including meropenem, the most broad spectrum antibiotic. ${ }^{1}$ Incidence of CPE in Canada is increasing: from five cases in 2008 to 779 in 2016 (Dr. Michael Mulvey, National Microbiology Laboratory, Canadian Science Centre for Human and Animal Health, Winnipeg, Man.; personal communication, 2017), and outbreaks in hospitals have been reported. ${ }^{2}$ In 2017, the World Health Organization named CPE priority 1 pathogens. ${ }^{3}$

2

\section{CPE is most commonly acquired in hospitals and long-term care facilities}

Carbapenemase resistance is usually encoded by plasmids that can move between bacteria. ${ }^{1}$ Carbapenemase-producing Enterobacteriaceae reside in the gastrointestinal tract and are endemic in hospitals and long-term care facilities in many countries, including the United States. ${ }^{1}$ Patient-to-patient transmission occurs by contaminated hands of health care providers or contaminated shared patient equipment. ${ }^{2}$

\section{3}

\section{CPE infection has similar clinical manifestations to those of other gram-negative bacteria}

Infection caused by CPE will present with symptoms and signs typical of other gram-negative infections (e.g., urinary tract infection, sepsis). ${ }^{1}$ Colonization of CPE has no symptoms. In Canada, CPE are reliably identified from routine bacterial cultures or screening specimens (e.g., rectal swabs).

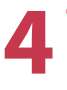

\section{There are limited treatment options for CPE}

Colonization does not require treatment. ${ }^{2}$ Antibiotic treatment options for CPE infection are limited at present and for the foreseeable future; last-line antibiotics (e.g., colistin) may be required. ${ }^{2}$ Mortality from bacteremia caused by CPE ranges from $25 \%$ to $50 \% ;{ }^{4}$ expert consultation should be sought for all CPE infections.

\section{5}

\section{Preventing the spread of CPE requires multiple measures}

Measures to prevent spread include requiring screening at-risk patients upon admission to hospital, providing care with gowns and gloves in a private room, meticulous hand hygiene, routine cleaning and disinfection of shared patient equipment, effective hospital cleaning and optimal antibiotic prescribing by physicians. ${ }^{2,5}$ Alberta and British Columbia have made CPE a reportable disease, which may facilitate surveillance and timely interventions.

\section{References}

1. Nordmann P, Naas T, Poirel L. Global spread of carbapenemase producing Enterobacteriaceae. Emerg Infect Dis 2011;17:1791-8.

2. Ontario Agency for Health Protection and Promotion, Provincial Infectious Diseases Advisory Committee. Annex A: screening, testing and surveillance for antibioticresistant organisms (AROs) - in all health care settings [annex to routine practices and additional precautions in all health care settings, 3rd ed.]. Toronto: Public Health Ontario; 2013. Available: www.publichealthontario.ca/ en/eRepository/PIDAC-IPC_Annex_A_Screening_Testing _Surveillance_AROs_2013.pdf(accessed 2017 Jan. 27).

3. Global priority list of antibiotic-resistant bacteria to guide research, discovery, and development of new antibiotics. Geneva: World Health Organization; 2017. Available: www.who.int/medicines/publications/WHO-PPL-Short _Summary_25Feb-ET_NM_WHO.pdf?ua=1 (accessed 2017 Mar. 10)

4. Falagas ME, Tansarli GS, Karageorgopoulos DE, et al. Deaths attributable to carbapenem-resistant Enterobacteriaceae infections. Emerg Infect Dis 2014;20:1170-5.

5. Guidance: infection prevention and control measures for healthcare workers in all healthcare settings: carbapenemresistant gram-negative bacilli. Ottawa: Public Health Agency of Canada; 2010. Available: www.phac-aspc.gc.ca/ nois-sinp/guide/ipcm-mpci/pdf/guide-eng.pdf (accessed 2017 Mar. 14).

\section{Competing interests: None declared.}

This article has been peer reviewed.

Affiliations: Public Health Ontario (Johnstone, Patel); Dalla Lana School of Public Health (Johnstone), University of Toronto; Department of Laboratory Medicine and Pathobiology (Patel), University of Toronto, Toronto, Ont.

^PIDAC-IPC: Chingiz Amirov, Anne Bialachowski, Sandra Callery, William Ciccotelli, Maureen Cividino, Judy Dennis, Gary Garber, Susy Hota, Kevin Katz, Allison McGeer, Matthew Muller, Vydia Nankoosingh, Catherine Richard, Herveen Sachdeva, Mary Vearncombe

Correspondence to: Jennie Johnstone, jennie. johnstone@oahpp.ca 